\title{
Intradural extramedullary spinal inflammatory myofibroblastic tumor: case report and literature review
}

\author{
Ilyess Zemmoura $\cdot$ Abderrahmane Hamlat $\cdot$ \\ Xavier Morandi
}

Received: 28 March 2010/Revised: 31 January 2011/Accepted: 25 March 2011/Published online: 6 April 2011

(C) Springer-Verlag 2011

\begin{abstract}
The authors present the case of an inflammatory myofibroblastic tumor that involves the cervical spinal cord meninges, presenting in a manner mimicking en plaque meningioma, which has never been previously reported. During the first surgical procedure, which did not involve exploration of the intradural space, inflammatory epidural tissue was found. We performed a second operation to remove the tumor that was finally intradural, dural-based and very tough. Imaging studies, surgical findings, and histopathological examinations were used to support the diagnosis. Intradural extramedullary inflammatory myofibroblastic tumor is a rare entity that has only been described nine times in the literature. Surgery remains the treatment of choice. Although histologically benign, spinal inflammatory myofibroblastic tumor can be aggressive and requires a large resection and long-term follow-up of the entire central nervous system with magnetic resonance imaging.
\end{abstract}

Keywords Inflammatory myofibroblastic tumor . Cervical spine $\cdot$ Intradural mass · Inflammatory pseudotumor P Plasma cell granuloma

\section{Introduction}

Inflammatory myofibroblastic tumor (IMT) is a histologically benign ubiquitous lesion usually described in the lung

I. Zemmoura · A. Hamlat · X. Morandi

Department of Neurosurgery, Pontchaillou Hospital,

University of Rennes, Rennes, France

I. Zemmoura ( $₫)$

Service de Neurochirurgie, Hôpital Bretonneau,

CHU de Tours, Tours, France

e-mail: ilyess.zemmoura@yahoo.fr
[1] and the orbit. Although it has been described using various terms, such as "inflammatory pseudotumor" or "plasma cell granuloma", IMT is the more appropriate term as recognized in the 2002 World Health Organization Classification [2]. Spinal meningeal involvement is rare. To the best of our knowledge, only nine cases of intradural extramedullary spinal lesions [3-11] have been reported in the literature. We report the case of an intradural extramedullary IMT of the cervical spine in a 43-year-old male. The aims of this report are to describe a new case of this rarely reported location of IMT and to place emphasis on clinical, radiological, and surgical findings through a literature review.

\section{Case report}

A 43-year-old male had a 4-month history of nocturnal posterior cervical pain. His past medical history was uneventful. He reported a progressive radicular pain in his left upper limb at C6 and C7. He had developed paresthesia in the first three left fingers. His neurological examination showed weakness in pronation and the interosseous and lumbrical muscles of the left hand. Tricipital and ulnar pronator reflexes were bilaterally absent. There was no sign of spinal cord compression.

$\mathrm{X}$-rays of the cervical and thoracic spine revealed a loss of cervical lordosis. The Computed Tomography (CT) scan of the cervical and thoracic spine was normal. The results of laboratory tests including blood cell count, C-reactive protein and erythrocyte sedimentation rate were normal. Magnetic Resonance Imaging (MRI) showed a mass at C6-T1 (Fig. 1), anterior to the spinal cord, infiltrating bilaterally $\mathrm{C} 7$ and $\mathrm{T} 1$ neural foramina. The mass was isointense to the spinal cord on T1-weighted images with 

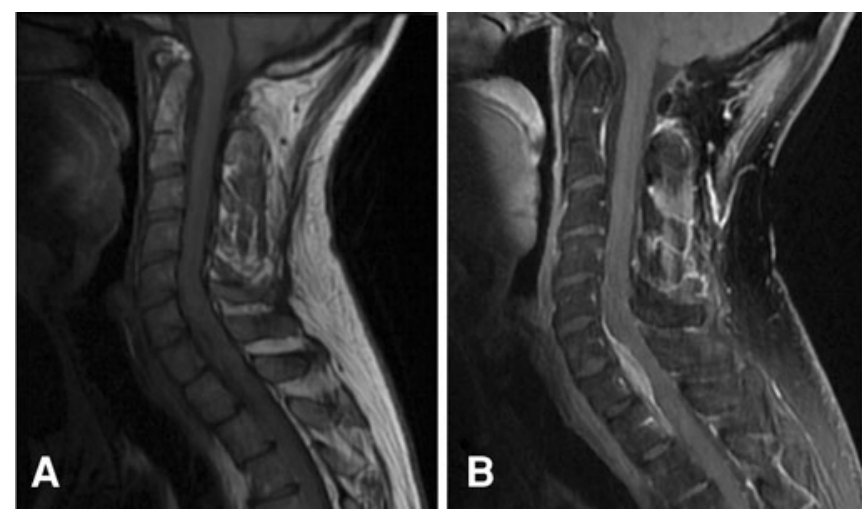

Fig. 1 Preoperative magnetic resonance imaging (MRI). a Sagittal T1-weighted image showing a tumor isointense to the spinal cord, at C6 to T1. b Homogeneous enhancement of the tumor after injection of gadolinium. c Sagittal T2-weighted image: the tumor appears as

homogeneous contrast enhancement, and hypointense on T2-weighted images.

The tumor was initially considered epidural and the patient was operated via a posterior approach with conservation of the posterior joints. During surgery, the anterior epidural tissues were inflammatory with thickening of the anterior dura mater. Histopathological examination of the epidural specimen showed non-specific diffuse chronic inflammation of a fibrous tissue.

Postoperative MRI confirmed that the tumor had been missed. The neurological examination was unchanged.

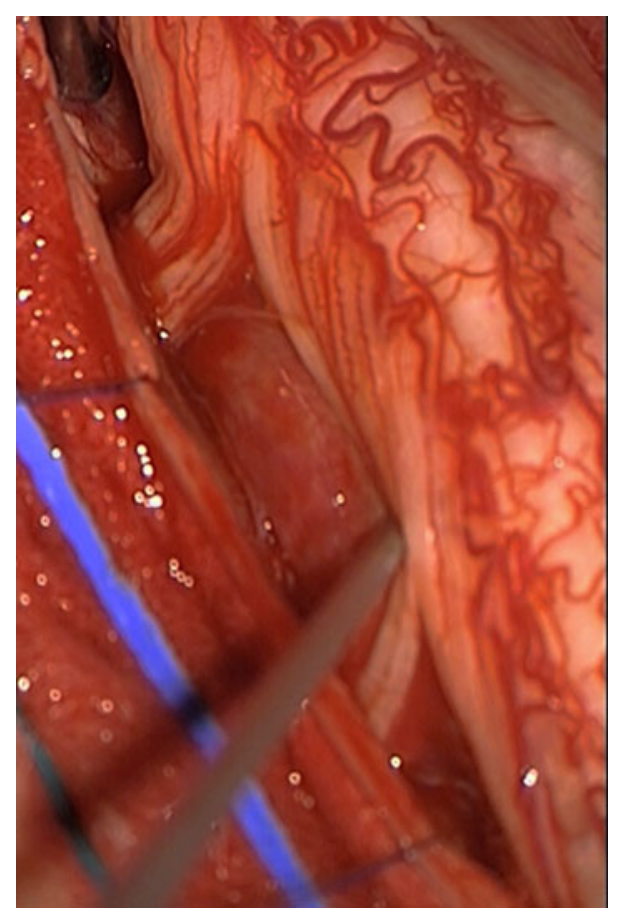

Fig. 2 Intraoperative photograph. The tumor is located anterior to the spinal cord and nerve roots

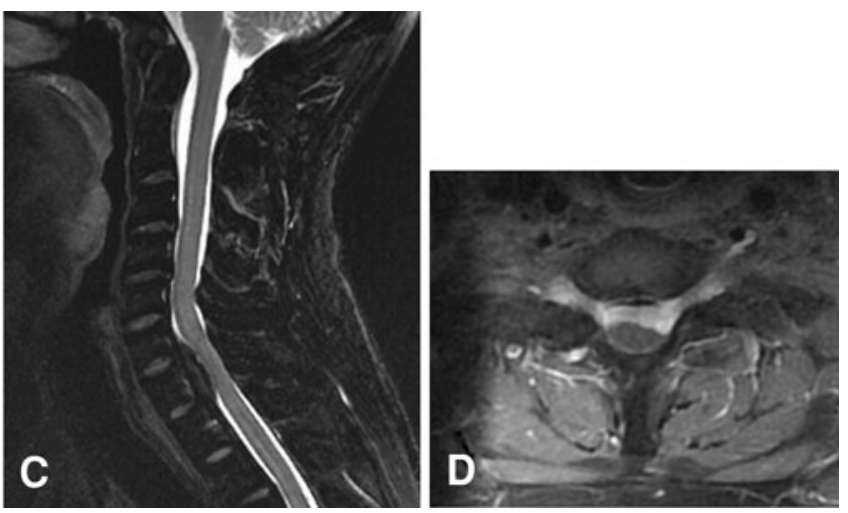

very low signal intensity. d Axial post-contrast T1-weighted image: bilateral foraminal contrast enhancement interpreted as extension of the tumor to the $\mathrm{C} 7$ neural foramina

Therefore, the patient underwent a second surgical procedure 1 month later. Posterior intradural exploration revealed a tough, white, fibrous intradural extramedullary tumor (Fig. 2), anterior to the dentate ligament. A piecemeal resection was performed with optical magnification. The tumor was easily dissected from the spinal cord and nerve roots, but was firmly attached to the dura mater which was, however, finally spared. We could see the lateral tumor borders, anteriorly surrounding the $\mathrm{C} 7$ and $\mathrm{T} 1$ nerve roots bilaterally, with no extension to the foramina. Complete removal was confirmed by immediate postoperative MRI (Fig. 3). Histopathological examination showed a fibrous tissue mass infiltrated with a mixed population of lymphocytes, plasma cells and macrophages, thereby confirming the diagnosis of IMT (Fig. 4).

After surgery, there was a temporary worsening of weakness and paresthesia occurring in both upper extremities. The patient gradually improved. At the time of the most recent follow-up, 14 months after the last surgery, he still had paresthesia in the left index and interosseous and lumbrical muscle weakness in the left hand.

His brain MRI was normal. The thoracic and abdominal CT scan showed a $0.6 \mathrm{~cm}$ nodule in the upper lobe of the right lung. It was considered non-specific by pneumologists who suggested only a CT check-up at 6 months.

\section{Discussion}

Among the extrapulmonary locations [12, 13] of IMT, spinal involvement is very rare. To the best of our knowledge, since the first description by Eimoto et al. [5], only nine cases of intradural extramedullary [3-11] tumors have been reported in the literature (Table 1). A few other cases of epidural [14-17] or intramedullary [18-20] spinal IMT have been reported. 
Fig. 3 Postoperative MRI on post-contrast T1-weighted sequences showing complete removal of the tumor. a sagittal image. b axial image
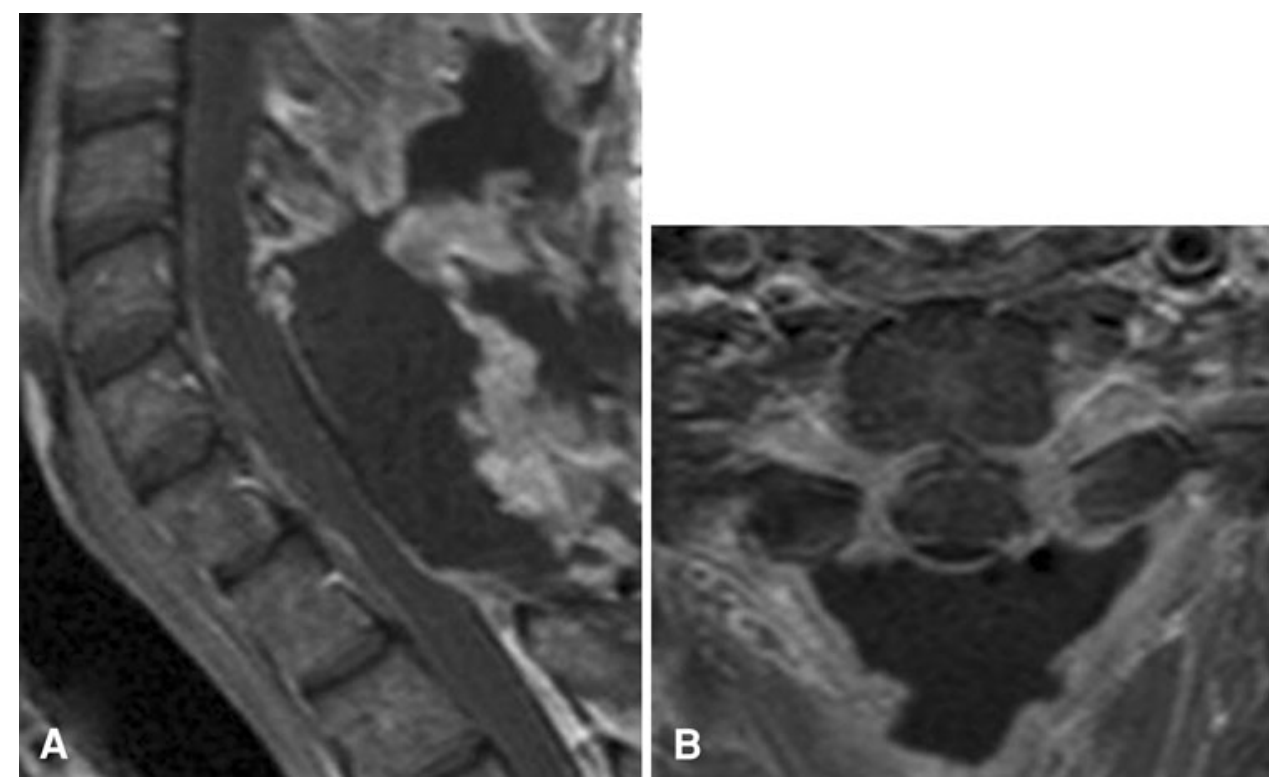
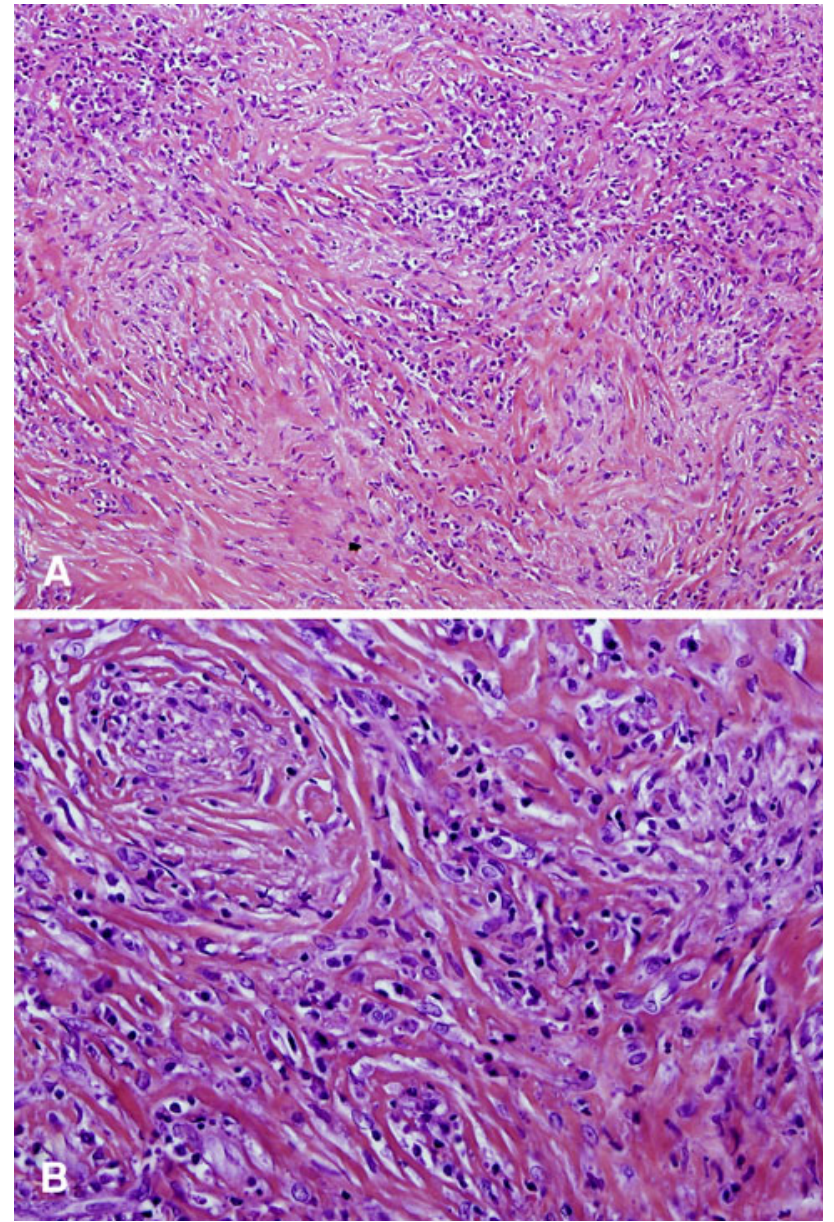

Fig. 4 Pathology specimen, hematoxylin and eosin. a (original magnification $\times 100$ ). There are compact fascicular and myxoid areas. b (original magnification $\times 200$ ). Spindle cells are mixed with numerous lymphocytes and plasma cells
According to the previous cases reported, the time to diagnosis of intradural extramedullary spinal IMT ranges from 2 to 48 months. The present case was revealed by radicular pain, whereas the most common clinical features are spinal cord compression symptoms. The nocturnal character of the pain oriented us to an inflammatory lesion.

MRI features of intradural extramedullary IMT were poorly documented in four $[3,6,9,11]$ of the nine cases reported. In the present case, MRI showed a mass that was isointense on T1-weighted sequences and hypointense on T2-weighted sequences. Contrast enhancement was intense and homogeneous, similar to that of vascular or inflammatory lesions. The tumor was anterior to the spinal cord with scarcely demarcated lateral extension to the $\mathrm{C} 7$ and $\mathrm{T} 1$ neural foramina. The radiological features of the extramedullary tumor were discussed with neuroradiologists. The diagnosis suggested was either an epidural tumor such as a sarcoma, or an intradural tumor such as an en plaque meningioma.

Our first diagnosis was that of an epidural tumor based on MRI foraminal enhancement interpreted as lateral extension of the tumor, together with clinical features of an inflammatory tumor, and the fact that en plaque meningiomas of the spine are very rare [21-24], often occur in middle-aged female patients and are more likely to cause spinal cord compression than radicular symptoms [21]. The pitfall in our management was that as no tumor was found in the epidural space, intradural exploration should have followed. However, this was not the case as we believed the tumor to be an epidural sarcoma.

Two different surgical approaches were discussed. An anterior approach would have allowed an en bloc resection 


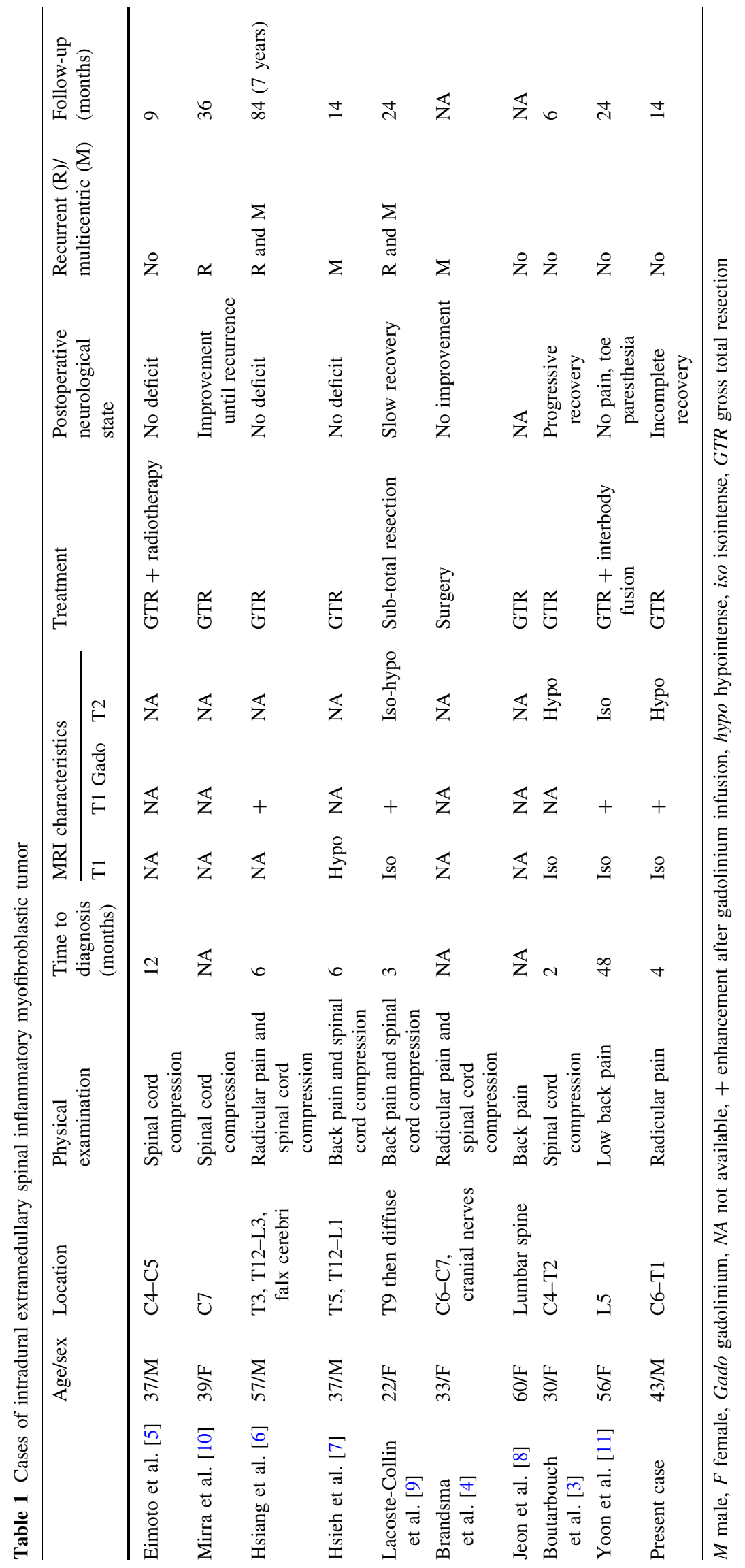


to be performed, but the tumor was posterior to three vertebral bodies, imposing an extensive three-level corporectomy. We therefore chose the posterior approach with laminectomy and conservation of the posterior joints. A piecemeal resection was performed bilaterally to protect the spinal cord. The tumor was more fibrous and tougher than a meningioma, and resection was difficult.

Surgical excision is the best way to reach a precise diagnosis, as radiological findings cannot differentiate the tumor from a meningioma. Complete removal remains the recommended treatment, although other treatments such as steroid therapy [25], antibiotics, radiotherapy [26, 27], chemotherapy [5, 10, 13] or $\mathrm{CO}_{2}$ laser [28] have been tested on other locations of IMT with good results.

Of the nine cases of intradural extramedullary IMT reported in the literature, five were recurrent $[3,7-9]$ or multicentric $[3,8,9,12]$ in the central nervous system (CNS). We therefore believe it is important to perform an initial MRI check-up of the entire CNS and provide longterm follow-up. There is no apparent histological difference between recurrent and non-recurrent forms. Lacoste-Collin et al. [9] suggested studying the anaplastic lymphoma kinase (ALK) gene that may be correlated with a higher recurrence rate. The short follow-up of our case cannot exclude a recurrent form and we did not study the ALK gene.

IMT should be considered as a possible etiology of intradural extramedullary spinal mass. MRI features of intradural extramedullary spinal IMT, which have not been described previously, are not specific and surgery is the only way to reach a diagnosis. Surgeons should be aware of its possible tough consistency as it may influence the surgical approach. As recurrent or multicentric forms are common, long-term follow-up should be offered.

Conflict of interest None.

\section{References}

1. Bahadori M, Liebow AA (1973) Plasma cell granulomas of the lung. Cancer 31:191-208

2. Fletcher C, Unni KK, Mertens F (2002) Pathology and genetics of tumors of soft tissue and bone. World Health Organization classification of tumors. IARC press, Lyon, France

3. Boutarbouch M, Arkha Y, Rifi L, Derraz S, El Ouahabi A, El Khamlichi A (2008) Intradural cervical inflammatory pseudotumor mimicking epidural hematoma in a pregnant woman: case report and review of the literature. Surg Neurol 69:302-305. doi: 10.1016/j.surneu.2006.12.056

4. Brandsma D, Jansen GH, Spliet W, Van Nielen K, Taphoorn MJ (2003) The diagnostic difficulties of meningeal and intracerebral plasma cell granulomas-presentation of three cases. J Neurol 250:1302-1306. doi:10.1007/s00415-003-0200-7

5. Eimoto T, Yanaka M, Kurosawa M, Ikeya F (1978) Plasma cell granuloma (inflammatory pseudotumor) of the spinal cord meninges: report of a case. Cancer 41:1929-1936
6. Hsiang J, Moorhouse D, Barba D (1994) Multiple plasma cell granulomas of the central nervous system: case report. Neurosurgery 35:744-747

7. Hsieh PC, Lin CN (1995) Multicentric plasma cell granuloma of spinal cord meninges. Clin Orthop Relat Res (317):188-192

8. Jeon YK, Chang KH, Suh YL, Jung HW, Park SH (2005) Inflammatory myofibroblastic tumor of the central nervous system: clinicopathologic analysis of 10 cases. J Neuropathol Exp Neurol 64:254-259

9. Lacoste-Collin L, Roux FE, Gomez-Brouchet A, Despeyroux ML, Uro-Coste E, Coindre JM, Delisle MB (2003) Inflammatory myofibroblastic tumor: a spinal case with aggressive clinical course and ALK overexpression. Case report. J Neurosurg 98:218-221

10. Mirra SS, Tindall SC, Check IJ, Brynes RK, Moore WW (1983) Inflammatory meningeal masses of unexplained origin. An ultrastructural and immunological study. J Neuropathol Exp Neurol 42:453-468

11. Yoon SH, Kim KJ, Chung SK, Kim HJ, Choe G, Chung SB, Jin YJ (2009) Inflammatory myofibroblastic tumor in the intradural extramedullary space of the lumbar spine with spondylolisthesis: case report and review of the literature. Eur Spine J 19(Suppl 2):S153-S157

12. Coffin CM, Humphrey PA, Dehner LP (1998) Extrapulmonary inflammatory myofibroblastic tumor: a clinical and pathological survey. Semin Diagn Pathol 15:85-101

13. Coffin CM, Watterson J, Priest JR, Dehner LP (1995) Extrapulmonary inflammatory myofibroblastic tumor (inflammatory pseudotumor). A clinicopathologic and immunohistochemical study of 84 cases. Am J Surg Pathol 19:859-872

14. Gilliard C, De Coene B, Lahdou JB, Boutsen Y, Noel H, Godfraind C (2000) Cervical epidural pseudotumor and multifocal fibrosclerosis. Case report and review of the literature. J Neurosurg 93:152-156

15. Roberts G, Farrell M, Allcutt D (2001) Spinal inflammatory pseudotumours. Br J Neurosurg 15:197-198

16. Roberts GA, Eldridge PR, Mackenzie JM (1997) Case report: inflammatory pseudotumour of the spine, with literature review. Br J Neurosurg 11:570-572

17. Seol HJ, Kim SS, Kim JE, Lee SH, Won JY (2005) Inflammatory pseudotumor in the epidural space of the thoracic spine: a case report and literature review of MR imaging findings. AJNR Am J Neuroradiol 26:2667-2670. doi:26/10/2667[pii]

18. Aizawa T, Sato T, Tanaka Y, Kishimoto K, Watanabe M, Kokubun S (2002) Intramedullary plasma cell granuloma in the cervicothoracic spine. Case report. J Neurosurg 97:235-238

19. Kilinc M, Erturk IO, Uysal H, Birler K, Evrenkaya T, Akkalyoncu BB (2002) Multiple plasma cell granuloma of the central nervous system: a unique case with brain and spinal cord involvement. Case report and review of literature. Spinal Cord 40:203-206. doi:10.1038/sj.sc.3101271

20. Lee M, Epstein FJ, Rezai AR, Zagzag D (1998) Nonneoplastic intramedullary spinal cord lesions mimicking tumors. Neurosurgery 43:788-794 discussion 794-785

21. Caroli E, Acqui M, Roperto R, Ferrante L, D'Andrea G (2004) Spinal en plaque meningiomas: a contemporary experience. Neurosurgery 55:1275-1279 discussion 1279

22. Frank BL, Harrop JS, Hanna A, Ratliff J (2008) Cervical extradural meningioma: case report and literature review. J Spinal Cord Med 31:302-305

23. Gamache FW Jr, Wang JC, Deck M, Heise C (2001) Unusual appearance of an en plaque meningioma of the cervical spinal canal. A case report and literature review. Spine (Phila Pa 1976) 26:E87-E89

24. Messori A, Rychlicki F, Salvolini U (2002) Spinal epidural enplaque meningioma with an unusual pattern of calcification in a 
14-year-old girl: case report and review of the literature. Neuroradiology 44:256-260

25. Albizzati C, Ramesar KC, Davis BC (1988) Plasma cell granuloma of the larynx (case report and review of the literature). J Laryngol Otol 102:187-189

26. Pettinato G, Manivel JC, Insabato L, De Chiara A, Petrella G (1988) Plasma cell granuloma (inflammatory pseudotumor) of the breast. Am J Clin Pathol 90:627-632
27. Warter A, Satge D, Roeslin N (1987) Angioinvasive plasma cell granulomas of the lung. Cancer 59:435-443

28. Satomi F, Mori H, Ogasawara H, Kumoi T, Uematsu K (1991) Subglottic plasma cell granuloma: report of a case. Auris Nasus Larynx 18:391-399 